\title{
Cancer and nutrition: role of amino acids (AA) for the regulation of hepatocellular apoptosis Miriam Mayer ${ }^{1}$, Adolf Ellinger ${ }^{2}$, Anneliese Karwan ${ }^{1}$, Rolf Schulte-Hermann ${ }^{1}$ and Wilfried Bursch*1
}

\author{
Address: ${ }^{1}$ Department of Medicine I, Institute of Cancer Research, Research Unit Toxicology and Prevention, Medical University of Vienna, Austria \\ and ${ }^{2}$ Center for Anatomy and Cell Biology, Department of Cell Biology and Ultrastructure Research, Medical University of Vienna, Austria \\ Email: Wilfried Bursch* - wilfried.bursch@meduniwien.ac.at \\ * Corresponding author
}

from 13th Scientific Symposium of the Austrian Pharmacological Society (APHAR). Joint Meeting with the Austrian Society of Toxicology (ASTOX) and the Hungarian Society for Experimental and Clinical Pharmacology (MFT)

Vienna, Austria. 22-24 November 2007

Published: I4 November 2007

BMC Pharmacology 2007, 7(Suppl 2):A64 doi:I0.1 I86/I47I-2210-7-S2-A64

This abstract is available from: http://www.biomedcentral.com/I47I-22/0/7/S2/A64

(C) 2007 Mayer et al; licensee BioMed Central Ltd.

Since decades nutrition is known to play a central role in development of cardiac diseases, cancer and diabetes. However, the causative nutritional factors and their mode of action are not well understood. Accumulating evidence suggest that certain nutrients (including glucose and AA) may regulate cell signalling events/gene expression independently of hormones, possibly acting through specific nutrient "sensor" mechanisms [1]. Previous in vivo studies by ourselves on the regulation of rat hepatocyte proliferation and apoptosis revealed that the lack of glucose and/or AA blocks the initiation of DNA synthesis $\left(\mathrm{G}_{1} / \mathrm{S}\right.$ transition). Furthermore, feed restriction favoured apoptosis in rat liver. Here we report on the role of AA for apoptosis of human hepatoma cells (HCC-1.2). The following changes in AA composition - as compared to standard RPMI 1640 medium - exerted a pro-apoptotic action, without and with TGF- $\beta 1$ treatment: (1) deprivation of branched chain AA, with Val > Leu > Ile when tested individually; (2) deprivation of Phe, Trp, Lys, Met, Thr, either as group or, with the exception of Met, when tested individually; (3) deprivation of His and Gln seemed less effective than the other individual AA tested; (4) occurrence of autophagy was demonstrated light- and electron-microscopically. In summary, this first series of experiments revealed HCC- 1.2 cells sensitive to the AA deprivation, rendering this model suitable for studying pharmacological actions of AA.

\section{References}

I. Kimball SR, Jefferson LS: New functions for amino acids: effects on gene transcription and translation. Am J Clin Nutr 2006, 83:500S-507S. 